\title{
Metáforas presidenciales durante el estallido social chileno de 2019
}

\author{
Presidential metaphors during the 2019 Chilean social outbreak
}

\author{
Amanda Valenzuela-Valenzuela \\ Fundación Kimntrum, Concepción, Chile \\ avalenzuelavakimntrum.org \\ https://orcid.org/0000-0003-4961-6976
}

\author{
Ricardo Cartes-Velásquez \\ Fundación Kimntrum, Concepción, Chile \\ rcartesvakimntrum.org \\ https://orcid.org/0000-0001-5831-7324
}

\section{Resumen}

En octubre del 2019 ocurrieron una serie de manifestaciones a lo largo de Chile. El objetivo de este artículo es describir las metáforas emitidas por el presidente de Chile, Sebastián Piñera, en sus discursos realizados entre el 18 y 25 de octubre, en contexto del "Estallido Social" de Chile. Las metáforas fueron identificadas y analizadas desde el enfoque de la dinámica del discurso aplicado a la metáfora. Se identificaron metáforas vinculadas a: Agenda Social, Estados de Emergencia, Manifestaciones y Necesidades de la Población. Se observa que el Presidente durante la primera semana del estallido social ve las manifestaciones como obstáculos en el "camino" del desarrollo del país; aquí, destaca la "guerra contra un enemigo poderoso" planteado como el gran obstáculo a ser derrotado y donde él debe guiar a la población hacia el desarrollo por medio de la Agenda Social, protegiendo lo "construido" a lo largo de la historia chilena.

Palabras clave: análisis del discurso, Chile, discursos presidenciales, estallido social, metáfora conceptual.

\begin{abstract}
In October 2019, a series of protests took place throughout Chile. The aim of this paper is to describe the metaphors emitted by the president of Chile, Sebastián Piñera, in his speeches made between October 18 and 25, in the context of Chile's "Social Outbreak". The metaphors were identified and analyzed from the approach of the dynamics of discourse applied to the metaphor. Metaphors related to: Social Agenda, States of Emergency, Manifestations and Needs of the Population were identified. It is observed that the President during the first week of the social outbreak sees the protests as obstacles in the "pathway" of the country's development; here the "war against a powerful enemy" stands out as the great obstacle to be defeated and where he must guide the population towards development through the Social Agenda, protecting what is "built" throughout Chilean history.
\end{abstract}

Keywords: discourse analysis, Chile, presidential speeches, social outbreak, conceptual metaphor. 


\section{Introducción}

La metáfora conceptual es parte de la lingüística cognitiva, donde la metáfora no es utilizada como una figura literaria, sino como una forma de describir ideas o experiencias de difícil manifestación, en términos de una expresión más concreta, usualmente en el lenguaje cotidiano de las personas (Escandell, 2007; Landau, Robinson \& Meier, 2014; Seung, Park \& Jung, 2015; Ungerer \& Schmid, 2006). Son prominentes en el discurso de quienes expresan vivencias emotivas y/o pensamientos abstractos, puesto que permiten concretar dichos mensajes (Gibbs, 2008). Puesto que la metáfora influye en nuestro pensamiento y actuar, se considera como un elemento de gran importancia en los discursos políticos, permitiendo la comprensión de conceptos complejos, además de actuar como un instrumento de persuasión (Penninck, 2014). Se considera a la metáfora como el proceso más eficiente a la hora de transmitir un mensaje político (Digonnet, 2014).

En octubre del 2019, se inició el llamado “Estallido Social" en Chile, expresión metafórica en sí misma, que se origina en el aumento de la tarifa del Metro de Santiago en 30 pesos (Agencia AFP, 2019; Paúl, 2019), que llevó a la realización de evasiones masivas y posteriores manifestaciones, tras las cuales se declaró Estado de Emergencia en múltiples regiones del país (Paúl, 2019). Durante esa primera semana se sucedieron una serie de enfrentamientos, con incendios y ataques al Metro, que obligan a cerrar sus estaciones; seguido por masivas manifestaciones que llevan al enfrentamiento con las fuerzas de orden, el decreto de toque de queda en las principales ciudades y la militarización del estallido desde el discurso de guerra y la puesta de militares en las calles. Esa semana finaliza con manifestaciones aún mayores y una huelga general del país que no responde a las medidas sociales ofertadas por el ejecutivo (Agencia AFP, 2019).

A partir del 18 de octubre, el Presidente de la República, Sebastián Piñera, realiza múltiples discursos públicos desde el Palacio de la Moneda', transmitidos en vivo a nivel nacional. Se considera que la situación chilena es de caos, con manifestaciones a lo largo del país que se extendieron por varias semanas (Agencia AFP, 2019). Esto ha llevado a distintos comentarios y opiniones públicas por parte de los distintos partidos políticos nacionales (Reyes,
2019), así como grupos vinculados a la academia, los que destacan como problemática principal a la desigualdad del país en el origen del descontento y la consecuente demanda de soluciones por parte de la población (Sepúlveda, 2019). Sin embargo, tras el transcurso de varios meses, no existe una caracterización clara de la génesis del estallido; la desigualdad se muestra como un elemento central, pero a ello se suma el abuso e impunidad de las élites, una institucionalidad ineficaz y que prioriza la rentabilidad económica por sobre el bienestar, el abandono del Estado en tanto garante de derechos básicos; todo ello ha provocado una serie de demandas insatisfechas en lo económico, lo político, lo ambiental, lo simbólico, entre otras esferas (Güell, 2019). Es en este estallido social "en progreso" o "en tránsito" o "en estudio" que, una de las pocas certezas es que el cambio constitucional (también "en progreso") se muestra como un ejercicio, en el más amplio sentido de la palabra (cívico, jurídico, social, discursivo, participativo, etc.), necesario para iniciar la resolución de los problemas que generaron el estallido (Leiva, 2020).

Las metáforas son recursos lingüísticos, empleados por los hablantes, y capaces de responder a los eventos actuales de un país (Valida, 2015), por lo cual con su análisis se pueden vislumbrar actitudes y pensamientos de quien las emite. En marco de lo expresado anteriormente, el objetivo de la presente investigación es describir las metáforas emitidas por el presidente de Chile, Sebastián Piñera, en sus discursos realizados entre el 18 y 25 de octubre, en contexto del "Estallido Social" de Chile. Diversos artículos se han referido a todo este proceso como Revuelta Social (Bauerle, 2019; Navarro \& Tromben, 2019) o Levantamiento Social (Rajevic, 2020; Márquez, Pérez \& Rodriguez, 2020), lo que claramente tiene una connotación distinta, ya desde el mismo plano metafórico. En este caso nos referiremos al proceso como estallido social en cuanto denominación usada con mayor frecuencia en los diversos medios, sin entrar en análisis que se alejan del objetivo ya planteado.

Este artículo se estructura en una sección de marco teórico que aborda una caracterización de la metáfora conceptual y su utilización en el discurso político. Seguido por la metodología basada en el procedimiento propuesto por el Pragglejaz Group (2007) y Cameron (2007), los resultados organizados en los cuatro tópicos identificados en los dis- 
cursos presidenciales, y cierra con la discusión y las conclusiones.

\section{Marco teórico}

La Metáfora Conceptual surge desde la Lingüística Cognitiva diferenciada de la metáfora como figura literaria que se estudia desde la antigüedad (Ekaterina, 2016). Desde la perspectiva conceptual, las metáforas son fundamentales en la producción de pensamiento y lenguaje, por lo cual son imprescindibles en la comunicación (Deignan, 2005), contrario a lo que ocurre en la visión de la metáfora como figura literaria, donde la metáfora es un simple recurso ornamental en el discurso (Lesz, 2011). Desde esta perspectiva, puede definirse la Metáfora Conceptual como aquella que permite la descripción de una experiencia o idea de difícil manifestación por su abstracción, en términos de una expresión más concreta (Escandell, 2007; Landau et al., 2014; Seung et al., 2015). Así, la metáfora permite la comprensión de un dominio conceptual en base a otro concepto de mayor compresión para el hablante que la emite (Sharifian en Xu \& Sharifian, 2017).

En el contexto de los discursos presidenciales, la metáfora se releva debido al poder que el lenguaje tiene dentro de la política, encontrándose en la gran mayoría de los discursos políticos (Borčić, Kanižaj \& Kršul, 2016). Esto se debe a que las metáforas tienen la capacidad de impactar e influir en la opinión pública, modificando la visión de mundo de las personas, por lo cual se prestan como herramientas útiles en la política (Penninck, 2014). En este contexto, las metáforas suelen enmarcarse en determinados aspectos conceptuales, como la guerra, las enfermedades, las máquinas, la construcción, los viajes, el deporte, entre otros (Borčić et al., 2016; Ekaterina, 2016).

A partir de las investigaciones de Lakoff y Johnson (1980), los estudios en metáfora se caracterizan por no clarificar el proceso de identificación y selección de metáforas. Por lo anterior, los lingüistas cognitivos cuentan con múltiples formas de interpretar y caracterizar las distintas expresiones metafóricas que se encuentran (Penninck, 2014). Lo anterior, ha generado múltiples críticas, puesto que las metáforas son identificadas sin una explicación de los criterios utilizados por el equipo investigador (Seung et al., 2015). Por ello, a través del Procedimiento para Identificación de Metáforas [MIP en inglés] (Pragglejaz Group, 2007) y la propuesta de Cameron (2007) sobre la aplicación del enfoque de la dinámica del discurso a la metáfora, pueden identificarse metáforas en distintos discursos, de una forma clara y explícita.

La propuesta de Cameron, la Metáfora Dinámica Sistemática, se contextualiza en el enfoque de la dinámica del discurso, en que la metáfora tiene aspectos que son simultáneamente lingüísticos, afectivos, socioculturales y cognitivos (Cameron, 2007). Por ello, la metáfora evidencia los pensamientos y las perspectivas de los hablantes, y se adaptan a cada interacción (Alarcón, 2019; Cameron, 2008). Por ende, la metáfora permite la creación de nuevas conceptualizaciones en base a lo dialógico, a la vez que facilita la estructuración de representaciones mentales (Alarcón, 2019; Cameron, 2008; Cameron et al., 2009; Castillo, 2019). Esto se debe a que las metáforas permiten la conexión de ideas que provienen de múltiples sistemas de pensamiento y el uso del lenguaje de quien las emite (Cameron et al., 2009), además de basarse en constructos mentales que involucran múltiples elementos que se integran conjuntamente (Fauconnier \& Turner, 2008).

En el caso del estallido social en Chile, Navarro y Tromben (2019) publicaron un análisis de los discursos presidenciales durante la época de las protestas y previo a estas. Dicho trabajo presenta un alcance amplio del discurso político, incluyendo: elecciones léxicas, colocaciones, opuestos binarios, palabras clave, evaluaciones, temas discursivos, metáforas, intertextualidad y estrategias discursivas. Dan cuenta de una discursividad que evoluciona desde una cómoda posición tecnocrática sustentada en una eficiencia del Estado, que luego se devela como ilusoria, hacia la conocida posición de "guerra contra un enemigo poderoso" que criminaliza en términos prácticos y simbólicos a los manifestantes. Para finalizar en una posición de solidaridad hacia las demandas del pueblo, cuestión que sólo ha aumentado la desconfianza a una élite que se muestra como desconectada de la realidad vivida por la mayoría de los chilenos.

Tal como destacan Navarro y Tromben (2019), los discursos tienen consecuencias a nivel social, cog- 
nitivo, moral y material. En el caso del discurso político en situaciones de crisis e inestabilidad, estas consecuencias se ejercen de manera más intensa, especialmente cuando estos discursos se realizan en cadena nacional y desde una posición de asimetría de poder, siempre enmarcados por una democracia con un presidencialismo hipertrofiado (Leiva, 2020).

\section{Metodología}

El presente estudio se realizó desde un enfoque cualitativo, con carácter exploratorio, por la falta de investigaciones que abordan los discursos del reciente estallido social en Chile. Para el corpus, se seleccionaron los discursos presidenciales a través de muestreo por criterio (Mejía, 2000). En este caso, el principal criterio de inclusión era que el discurso fuese emitido por el presidente Sebastián Piñera en cadena nacional, entre el 18 y 25 de octubre del 2019, ambas fechas inclusive, puesto que es la primera semana del llamado estallido social. Se recopiló un total de siete discursos, encontrados en el sitio web oficial de la Prensa Presidencial (Gobierno de Chile, 2019), transcripciones con una extensión de 729 a 1509 palabras. Sebastián Piñera es un político de derecha y empresario chileno, uno de las cinco mayores fortunas del país, ha sido senador (1990-1998) y presidente del partido Renovación Nacional (2000-2004), siendo elegido presidente de la República en dos periodos (2010-2014 y 2018-2022) (Gobierno de Chile, 2010).

Como primer paso, se leyeron la totalidad de los discursos seleccionados, para luego leerlos en búsqueda de metáforas, identificadas por medio del enfoque de la dinámica del discurso aplicado a la metáfora (Cameron, 2007). Para la definición de una metáfora, se contrasta el significado de cada ítem léxico, entre su significado contextual y el significado de diccionario, en base al procedimiento propuesto por el Pragglejaz Group (2007). El diccionario utilizado para los contrastes corresponde al Diccionario de la Lengua Española (Real Academia Española [RAE], 2018).

Las unidades léxicas fueron etiquetadas como expresiones metafóricas al encontrarse una diferencia entre el significado contextual de una unidad léxica, y su significado contemporáneo más básico del diccionario, siempre que pueda entenderse el significado contextual en base al significado básico (Alarcón, Díaz \& Vásquez, 2018). De acuerdo a la metodología propuesta por Cameron (2007), se denominó vehículo a la unidad léxica cuyo significado básico contrastó con el significado contextual del discurso. Posterior a la identificación de todos los vehículos, se procedió a agruparlos de acuerdo a sus categorías semánticas y semejanzas en significado. En paralelo, se asociaron los vehículos con temas claves o tópicos, establecidos según los objetivos de investigación. Este procedimiento fue realizado por ambos autores, con lo cual se contrastan los hallazgos, dándole mayor validez a los resultados. Se destaca que las conclusiones emergen verdaderamente de los datos y no están definidos a priori. No se incluyó un análisis del lenguaje paraverbal ya que ello implicaría adjetivar tonos, posturas, intensidades y otras características que no son concretamente expresadas por el emisor, sino más bien reconocidas por el receptor, lo que excede el alcance del Procedimiento propuesto por el Pragglejaz Group (2007).

\section{Resultados}

En total se identificaron 179 vehículos metafóricos, agrupados de acuerdo a similitud semántica. En este artículo se reportan las 9 agrupaciones de vehículos que presentaron más de 5 metáforas, estos fueron: Movimiento (25), Verticalidad (16), Camino (15), Construcción (13), Guerra (10), Visión (9), Gravedad (8), Voz (8) y Tamaño (7). En cuanto al contenido del discurso, se identificaron 4 tópicos, correspondientes a: Agenda Social, Estados de Emergencia, Manifestaciones y Necesidades de la población. En total se identificaron 179 vehículos metafóricos, agrupados de acuerdo a similitud semántica. En este artículo se reportan las 9 agrupaciones de vehículos que presentaron más de 5 metáforas, estos fueron: Movimiento (25), Verticalidad (16), Camino (15), Construcción (13), Guerra (10), Visión (9), Gravedad (8), Voz (8) y Tamaño (7).

En cuanto al contenido del discurso, se identificaron 4 tópicos, correspondientes a: Agenda Social, Estados de Emergencia, Manifestaciones y Necesidades de la población. 


\subsection{Agenda Social}

El tópico Agenda Social hace su aparición en el quinto discurso analizado, fechado el 23 de octubre. En este discurso, el Presidente Piñera anuncia la propuesta de Agenda Social, con la cual se espera responder a las necesidades de la población, y cuyos principales ejes fueron las pensiones, el aumento del ingreso mínimo, el freno al costo de la electricidad, mayores beneficios en salud, defensoría para las víctimas de delitos y nuevos impuestos para quienes gocen de rentas altas.

Al emplear metáforas de construcción, el Presidente se refiere a los contenidos de la Agenda Social como “los principales pilares de esta Agenda", expresión desde la cual se infiere que la Agenda Social es una construcción, afirmada en sus contenidos. Piñera enuncia que "el martes anuncié al país los pilares de una Nueva Agenda Social".

Se encontró sólo una manifestación de metáforas de guerra, en la que se habla de "una fuerte lucha para bajar los precios de los medicamentos". Las metáforas de movimiento se refieren a movimientos de desplazamiento, en los cuales se puede avanzar o retroceder, es decir, desplazamientos en el eje horizontal. Son las metáforas más abundantes en el total de los discursos, y también lo son dentro del tópico de Agenda Social. De las seis metáforas, cuatro pertenecen al dominio de impulsar (“... seguiremos impulsando las medidas administrativas..."; ; ... para poder impulsar esta iniciativa..."; "para que todos juntos podamos impulsar esta Agenda Social..."), donde se considera que las medidas de la Agenda Social son positivas, por lo cual "vale la pena llevarla adelante", entendiéndose que lo que se lleva hacia adelante es lo que se realiza. Por ello, el objetivo de la Agenda Social es visto como "sacar a nuestro país adelante".

Las metáforas de verticalidad son aquellas que refieren a la existencia de un arriba y un abajo, y al desplazamiento de ciertos elementos en ese eje. Las encontradas en el contexto de la Agenda Social refieren, principalmente, a altos y bajos. Se habla, entonces, sobre "sectores de más altos ingresos" y de los "sueldos más altos", con lo cual se vincula lo alto con grandes cantidades. De forma opuesta, se encuentran las expresiones referidas a "pensiones muy bajas", y a la "fuerte lucha para bajar los precios de los medicamentos", objetivos de la Agenda Social.
En las metáforas de visión se incluyen todas aquellas asociadas al sentido de la vista, y la percepción a través de la misma. De esta forma, el Presidente Piñera anuncia que "el proyecto [la Agenda Social] contempla que el Estado haga algo que nunca ha hecho", entendiéndose el contemplar no como la acción de ver, sino como el contenido del proyecto. Por otro lado, se habla de un "claro sentido de urgencia", y cómo "hemos escuchado, fuerte y clara" las demandas de la población chilena. Por ello, la claridad se asocia a lo comprensible y evidente, puesto que es más fácil de ser observado.

Las metáforas de voz son aquellas en las cuales se habla de una voz, pero que no es la voz real de una persona o un grupo de personas. En el tópico "Agenda Pública", sólo se encuentra una metáfora de voz, que aparece en la oración “... hemos escuchado, fuerte y clara, la voz de la gente expresando pacíficamente sus problemas...".

\subsection{Estados de Emergencia}

Tras varios días de manifestaciones en el contexto del estallido social, el Presidente Piñera declara Estado de Emergencia el 18 de octubre, el cual se prolongó por una semana en múltiples regiones del país. El tópico en cuestión emerge a partir del segundo discurso analizado, fechado el 19 de octubre.

Las metáforas de Movimiento encontradas refieren a la influencia del Estado de Emergencia en el proceso de "normalización" del país. Se habla que, desde el gobierno, se están “...haciendo nuestros mejores esfuerzos para avanzar hacia una normalización...", y que "necesitamos avanzar en lograr asegurar el resguardo del Orden Público". En estas metáforas, el moverse avanzando implica algo positivo. Se enuncia también que "esta normalización ya está en marcha...", con lo cual se reitera la noción que el estar metafóricamente en movimiento, avanzando, es estar haciendo progreso en determinadas temáticas.

En cuanto a las metáforas de tamaño, estas se refieren tanto al tamaño particular de un elemento, como a las referencias de variación de tamaño. En los discursos, se habla que los Estados de Emergencia fueron extendidos ("lo hemos extendido en la Región de Antofagasta"; "después lo extendimos a la Región de Valparaíso y Biobío..."), modificándo- 
se sus tamaños, si bien se refiere a un aumento de extensión física del Estado de Emergencia en distintas regiones.

Las tres metáforas encontradas dentro de la verticalidad, refieren al proceso de "levantar" los Estados de Emergencia: “... todos queremos levantar los Estados de Emergencia..."; "levantando los Estados de Emergencia..."; “... significa ir reduciendo y levantando los toques de queda...". Durante su permanencia, los Estados de Emergencia se encuentran sobre el país, y deben ser levantados para que terminen.

\subsection{Manifestaciones}

El estallido social se inicia con una serie de manifestaciones, desde la evasión del metro en Santiago, hasta marchas, barricadas y enfrentamientos con la policía nacional. Por ello, las alusiones a este tópico se presentan en la totalidad de discursos analizados. La noción de camino desde el lenguaje metafórico, es vista como la forma en la cual se "llega" a determinados resultados. Los caminos vendrían a ser metáforas de la vida misma, por lo cual el Presidente Piñera anuncia que espera "poder reemprender lo antes posible, todos juntos, los caminos del futuro...". También se habla que existen elementos que "en cierta forma está facilitando el camino de aquellos que quieren destruir nuestra democracia", y cómo estas personas van "destruyendo todo lo que se interpone en su camino". De esta forma, Piñera enuncia que las personas que realizan manifestaciones violentas destruyen los obstáculos que encuentran en el camino de su movilización, y que como país deben retomarse "los caminos del futuro", expresión utilizada en dos ocasiones, y que hace alusión a que el país se encuentra "detenido" en el camino mientras se mantengan las manifestaciones.

Los discursos del Presidente Piñera contienen metáforas de construcción relacionadas a la acción de construir, destruir y reparar. En el caso de destruir, se refiere a cómo los manifestantes están "destruyendo" la democracia y los sueños de las personas ("en cierta forma está facilitando el camino de aquellos que quieren destruir nuestra democracia"; "destruyen propiedades y sueños..."). Esto se vincula directamente con las metáforas de construir, que refieren en su totalidad a lo construi- do por la sociedad chilena "como el que con tanto esfuerzo hemos construido todos los chilenos..."; "nuestro estado de derecho y todo aquello que con tanto esfuerzo hemos construido", "obras que habíamos construido todos juntos con tanto esfuerzo..."). Como se puede apreciar, la construcción fue realizada en conjunto por la totalidad del país, y no ha sido una construcción sencilla, sino que ha requerido de esfuerzo por parte de los participantes. Esta fórmula se repite en tres discursos separados. Finalmente, en el caso de "reparar", la metáfora se aborda como un objetivo de parte del gobierno, para “reparar no sólo el daño físico, sino que también el daño moral" provocado por las manifestaciones.

En las metáforas de gravedad, se encuentran enunciados en los que se alude a los "graves hechos de violencia", los "graves atentados al orden público" y los "graves y reiterados ataques", los cuales refieren a parte de las manifestaciones realizadas durante la semana en la cual se realizaron los discursos analizados. Se añade que las manifestaciones "han afectado gravemente la libre circulación" y "han alterado gravemente el orden público". Se llega a hablar de "la delincuencia gravísima" y que hay personas que "han cometido esos gravísimos actos de delincuencia".

En el discurso hecho el 20 de octubre, el Presidente Piñera declara: "Estamos en guerra contra un enemigo poderoso". A lo largo de dicho discurso, en el tópico de manifestaciones, se utilizan metáforas asociadas a la guerra cinco veces. Se habla que quienes se manifiestan de forma violenta "están en guerra contra todos los chilenos...", por lo cual el Presidente Piñera declaró: "llamo a todos mis compatriotas a unirnos en esta lucha contra la violencia"; "yo le pido a todos mis compatriotas que nos unamos en esta batalla que no podemos perder". En este discurso, a través de esta metáfora, el Presidente Piñera establece una guerra entre los manifestantes identificados como violentos y el país como nación. Anteriormente, se había utilizado una metáfora agrupada en la misma categoría durante el discurso del 18 de octubre ("las personas que han cometido esos gravísimos actos de delincuencia enfrenten a la justicia"). Posterior al discurso del 20 de octubre, se utiliza una única vez en el último discurso analizado, del 25 de octubre, donde se dice que "nuestro Gobierno va a seguir combatiendo con todos los instrumentos que nos otorga la democracia". 
Dentro del tópico de manifestaciones, se emplean tres metáforas de movimiento. La primera, refiere a que "... Chile siempre ha sabido salir adelante", y se relaciona a la oración donde "sólo unidos lograremos dejar atrás y superar estos problemas y estas carencias". La situación de Chile en las manifestaciones se ve como una negativa, que debe ser superada, para "salir adelante". Esto se relaciona a las metáforas de camino. Por otro lado, se enuncia la existencia de "querellas que persiguen el objetivo", con lo cual se corporiza a las querellas, dándoles la capacidad de moverse para perseguir cosas u objetivos.

En las metáforas de tamaño, se caracterizan elementos abstractos como si tuviesen la capacidad de cambiar de tamaño. Así se habla del "gran dolor que sienten muchos chilenos", el "enorme esfuerzo por normalizar la situación" y el "esfuerzo gigantesco para lograr que mañana sea un día lo más normal posible". Otro ejemplo se encuentra en "los Bomberos de Chile que han tenido una tarea titánica para apagar incendios".

Sólo se presentan dos oraciones con metáforas de verticalidad dentro del tópico de manifestaciones, en ambos casos referidas a la profundidad de algo, es decir, lo que se encuentra más abajo. Se indica que: "El objetivo de este Estado de Emergencia es muy simple, pero muy profundo", y que el Presidente Piñera quiere "expresar" su "profundo agradecimiento y reconocimiento".

\subsection{Necesidades de la población}

Este tópico se refiere a las necesidades, demandas y peticiones de la población chilena, las cuales motivaron las manifestaciones que explotaron en un estallido social. Son estas necesidades las que motivaron la Agenda Social propuesta por el Gobierno, cuyas metáforas ya fueron presentadas.

En las metáforas de camino asociadas al tópico de necesidades de la población, el Presidente indica que "nos falta un largo camino por recorrer, y que tenemos que recorrerlo juntos". Para responder las necesidades de la población, tienen que transitar, en un mismo camino, el gobierno y la población. El proceso no será rápido ni inmediato, motivo que se percibe en que el camino a recorrer es largo. También se identifica la metáfora en ora- ciones como "cumplir sus sueños, es el norte, el principal norte que guía cada uno de los actos" y "motivaciones que han guiado e inspirado a nuestro Gobierno". Las necesidades de la población chilena cumplen el rol de guías en el camino que deben recorrer tanto el gobierno como la ciudadanía. Por último, al hablar del deber de un Presidente, Piñera anuncia que "incluye también abrir de par en par los caminos del diálogo, la colaboración, la buena voluntad y los acuerdos". Se ve como responsabilidad del Ejecutivo el permitir que se den las instancias de diálogo y demás para solucionar las necesidades de la población chilena.

En metáforas de construcción, tras reconocer la existencia de necesidades de la población, el Presidente Piñera comienza a hablar sobre "la construcción de un Gran Acuerdo Nacional", agradeciendo a las organizaciones ciudadanas, sociedad civil y representantes municipales y parlamentarios, por "su valioso aporte y constructiva actitud". Se añade que es respondiendo a las necesidades de la población chilena que "se construyen las democracias". Las propuestas, por lo tanto, son equivalentes a construcciones realizadas por varias partes, y las opiniones externas tienen carácter de ser constructivas, es decir, que pueden modificar lo ya existente.

En el tópico de necesidades de la población, se identifican dos metáforas agrupadas en la categoría de metáforas de guerra. La primera, refiere a las prioridades del Gobierno, expresadas como "centradas en combatir la delincuencia". Así, se ven dos polos en combate, la delincuencia y el gobierno. También se habla de las propuestas "para enfrentar y superar esta difícil situación”, donde se busca luchar para dar las soluciones a las necesidades de la población, y así volver a la normalidad. Estas son anteriores al discurso del 20 de octubre.

En cuanto a movimiento, la primera expresión metafórica corresponde a "Llegó el momento de recuperar el tiempo perdido, acelerar el ritmo y pasar a la acción, y con urgencia...". Las medidas del gobierno para solucionar las necesidades del pueblo se ven como un movimiento que debe ser acelerado, para conseguir rápidas soluciones. Se vincula esto a las metáforas de avance l“... Chile va a poder seguir avanzando..."; "Tenemos que estar unidos para avanzar hacia un Chile más libre"), el cual es visto como algo positivo para la realidad país. 
También están las metáforas de impulso ("seguir impulsando..."; "que nos permita impulsar, y con urgencia"), donde se ve que las necesidades son solucionadas a través de propuestas que impulsan el movimiento.

Dentro del tópico de necesidades de la población, las metáforas de verticalidad refieren a aspectos monetarios dentro de las peticiones y necesidades detectadas. Así, se considera que existe un "alto costo de la vida", es decir, que se requiere de una gran cantidad de recursos monetarios para poder solventar un buen vivir. Por otro lado, se identifica que se requiere de una "baja en el precio de los medicamentos" y "una baja en el precio y garantía de nuestros sistemas de salud".

Al igual que en tópicos anteriores, las metáforas de visión asocian la claridad con lo entendible, comprensible y evidente (“... hemos escuchado fuerte y clara, la voz de la gente..."; “... hemos recibido con humildad y claridad el mensaje que los chilenos nos han entregado..."). Además, el Presidente Piñera reconoció su ceguera política: "Reconozco y pido perdón por esta falta de visión...", donde la visión se refiere a comprender y anticiparse a las necesidades de la población. También se encuentra como última oración "eso tiene que ver con el Sistema de Transporte Público...", expresión utilizada para aludir a un tema con el cual guarda relación lo que se hablaba anteriormente.

En relación a voz, el Presidente Piñera utiliza en múltiples ocasiones variaciones de la expresión "escuchar la voz" de chilenos y chilenas. Con "escuchar la voz" no se refiere a escuchar las voces particulares de cada persona, sino que a darse por enterado de las peticiones y necesidades reales de distintos sectores. Piñera afirmó: “ ¡Por Dios que es útil escuchar la voz de los dirigentes!" y "Hemos escuchado con humildad, con atención, con compromiso, la voz, la poderosa voz de la gente".

\section{Discusión}

En los discursos del Presidente Piñera, se abordaron cuatro temas principales a través de metáforas. Estos corresponden a la Agenda Social, los Estados de Emergencia, las Manifestaciones y las Necesi- dades de la Población. Debe destacarse que varios de los grupos de vehículos encontrados en estos discursos se corresponden con aquellos determinados como comunes en otros estudios similares (Borčić et al., 2016; Ekaterina, 2016).

La Agenda Social refiere a las propuestas desde el Gobierno el 23 de octubre, para responder las Necesidades de la Población. Los ejes o "pilares" de esta Agenda son las pensiones, el ingreso mínimo, el costo de la electricidad, los beneficios en salud, la defensoría para víctimas de delitos y los impuestos de las personas con mayores ingresos. Con estas medidas, se busca "aliviar" a la población de sus problemas, puesto que se "luchará" con los problemas principales que aquejan a quienes se manifiestan. Para lograr solucionar los problemas, la Agenda Social debe "moverse" y "avanzar", para equiparar a quienes tienen sueldos "altos y bajos". A casi un año del estallido social, se mantienen pendientes algunas de las propuestas planteadas desde el gobierno, incluyéndose la realización del plebiscito constitucional (Fuentes, 2020) que fue aprobado por amplia mayoría el 25 de octubre de 2020.

Poco después de emitir el primer discurso analizado, el Presidente Piñera declaró Estado de Emergencia en múltiples puntos del país, que se extendieron por toda la semana. Estos Estados de Emergencia responden a las manifestaciones que afectaron la normalidad. Se busca, entonces, lograr "avanzar" hacia la normalización, para poder "levantar" los Estados de Emergencia y volver a la normalidad. Se le da un énfasis a la "violencia" hacia los bienes materiales, sin hacer mención a las posibles causas para la realización de dichos actos. Se observa, desde su perspectiva, que las manifestaciones son un obstáculo en el día a día y que deben terminar para que el país vuelva a la normalidad.

Por otro lado, se encuentran las manifestaciones, consistentes en marchas pacíficas y violentas, evasiones del metro, cacerolazos, entre otras formas de protesta. Desde el Gobierno, las manifestaciones se conciben como una paralización del "camino" normal de Chile, que afecta todo lo construido por la sociedad chilena. Se considera que en el contexto de las manifestaciones se han efectuado actos graves, por lo cual llega a declararse que el país se encuentra en "guerra". A través de esa metáfora, se define inmediatamente la existencia 
de, a lo menos, dos polos, con el Presidente solicitando ayuda en la "batalla". De acuerdo a Digonnet (2014), las metáforas de guerra en discursos políticos sirven para representar el poder de atacar, no el de defender, por lo cual se infiere que en este discurso se busca enfatizar la capacidad de respuesta por parte del Gobierno. Esto es consistente con lo planteado por Navarro y Tromben (2019), en cuanto a la evolución discursiva presidencial previa a las manifestaciones, donde la eficiencia tecnocrática se mostraba como una cualidad central de la administración del presidente Piñera.

El uso de metáforas de guerra continuamente en el discurso del 20 de octubre, llevó a que los manifestantes se apropiaron de la palabra a través de la consigna "no estamos en guerra", documentada incluso en medios internacionales (BBC Mundo, 2019), dándole nueva fuerza al movimiento que se intentaba frenar desde el Gobierno central. El uso de metáforas de guerra es descontinuado en discursos posteriores y se vira a una discursividad centrada en la solidaridad con los manifestantes y sus demandas (Navarro \& Tromben, 2019). En tal sentido, aun cuando la metáfora de guerra ha tomado preponderancia en los análisis, la metáfora central de los discursos presidenciales es el tándem camino-construcción materializados en la promesa de la Agenda Social y donde la guerra se muestra como una respuesta reactiva, un instrumento al servicio del resguardo de lo construido. Así, aparece continuamente que el país debe "salir adelante" y "avanzar", para "dejar atrás" todos los problemas asociados a las manifestaciones. Ya en el tópico de necesidades de la población, se añade el hecho que queda un "camino por recorrer" en conjunto entre el gobierno y la población chilena, convirtiéndose las necesidades de la población en "guías" en el camino. De acuerdo al Presidente, al saciar sus necesidades, la población podrá tener una vida más plena y feliz, con menos privaciones.

El desarrollo del país es reflejado como un camino en los discursos del Presidente Piñera, camino por el cual debe avanzarse, y en el que se encuentran las múltiples construcciones, materiales e inmateriales, que permiten la existencia de nuestra sociedad como la conocemos el día de hoy. La construcción es una metáfora usada ampliamente en los discursos políticos (Chilton \& Ilyin, 1993), como un proceso que se realiza a través del poder e impulso colectivo (Digonnet, 2014). El tener estas construc- ciones, permite acercar la sociedad a la plenitud, que es vista como el éxito. De acuerdo a esto, la función del Presidente es guiar en este camino, para lo cual debe frenar avances de quienes obstaculizan el status quo. La declaración de guerra se explica, entonces, como una medida para proteger esta visión, la del camino-construcción.

\section{Conclusiones}

A través del análisis de las metáforas empleadas, se observa que el Presidente durante la primera semana del estallido social ve las manifestaciones como obstáculos en el camino del desarrollo del país; aquí destaca la "guerra contra un enemigo poderoso" planteado como el gran obstáculo a ser derrotado. Por ello, en su visión, debe guiar a la población hacia el desarrollo por medio de la Agenda Social, protegiendo lo "construido" a lo largo de la historia chilena y que se materializa como una mantención del status quo, desde lo político y principalmente desde lo económico.

Si bien el discurso del Presidente Piñera luego de la primera semana cambia a un tono de mayor empatía con los manifestantes, el análisis de las metáforas conceptuales en sus discursos de la primera semana permite caracterizar con mayor precisión su visión política y el "camino" por el que el que, como Presidente, se siente llamado a guiar al país. En tal sentido, más allá de lo llamativo de las metáforas de guerra, la metáfora central en los discursos presidenciales de la primera semana corresponde al tándem camino-construcción.

En un contexto más amplio, la respuesta presidencial que se caracteriza desde la metáfora conceptual en este estudio, ha iniciado un proceso de respuesta a demandas sociales centradas en la profunda y transversal desigualdad que caracteriza a la sociedad chilena. A un año del estallido y posterior acuerdo partidista para un cambio constitucional, resulta de interés que las mismas cúpulas de poder en diversos ámbitos insistan en liderar cambios a los que, por acción u omisión, se han opuesto desde el retorno a la democracia. En este contexto resultará de interés continuar analizando desde la metáfora conceptual cómo las diversas fuerzas políticas tradicionales y emergentes construyen dis- 
cursos que propendan a la materialización de los cambios que la sociedad chilena demanda.

En cuanto a limitaciones del presente estudio, debe considerarse que las metáforas requieren de un contexto común entre emisor y receptor para ser entendidas (Pennick, 2014), por lo cual se presenta como útil el contraste entre análisis similares. Además, los discursos estudiados corresponden sólo a la primera semana del estallido social, es decir, abordan únicamente la respuesta inicial del presidente Piñera, y, por ello, no deben entenderse las palabras del ejecutivo como la totalidad de la estrategia del gobierno ante la situación. Deben realizarse más estudios similares a mediano y largo plazo para aportar a una mejor comprensión de este fenómeno, entendiendo que será un proceso en curso por mucho tiempo a la espera de una decisión sobre una nueva constitución para el país y que la actual pandemia generará un impacto profundo en el factor reconocido como causa principal del estallido social: la desigualdad.

\section{Notas}

1. Casa de Gobierno y sede del Presidente de Chile.

\section{Referencias}

Agencia AFP. (2019). La cronología del estallido social en Chile, según la Agencia AFP. Tele 13 [en línea]. Disponible en: https://bit.ly/33uMg4W. [Consulta 25/11/2019]

Alarcón, P., Díaz, C. \& Vásquez, V. (2018). Un análisis de columnas de opinión desde la metáfora conceptual. Signo y Pensamiento 37(83): 1-15.

Alarcón, P. (2019). El giro discursivo de la metáfora. (Apuntes de clase). Concepción, Chile: Programa de Magíster en Lingüística Aplicada, Facultad de Humanidades y Arte, Universidad de Concepción.

BBC Mundo. (2019). Protestas en Chile: “Estamos en Guerra”, la frase de Piñera que se le volvió en contra en medio de las fuertes manifestaciones. BBC Mundo [en línea]. Disponible en: https://bbc.in/37UPPVM. [Consulta 25/11/2019]

Bauerle, C. (2019). Los muros de la revuelta: La emergencia social grabada en las paredes. Cuadernos de Teoría Social 5(10): 138-150.

Borčić, N., Kanižaj, I., \& Kršul, S. (2016). Conceptual Metaphor in Political Communication. Zbornik Sveuilišta u Dubrovniku 3: 73-94.

Cameron, L. (2007). Patterns of metaphor in reconciliation talk. Discourse and Society 18: $197-222$.

Cameron, L. (2008). "Metaphor and Talk". En Gibbs, R. (Ed.), The Cambridge Handbook of Metaphor and Thought (pp. 17-211). Cambridge: Cambridge University Press.

Cameron, L., Maslen, R., Todd, Z., Maule, J., Stratton, P. \& Stanley, N. (2009). The Discourse Dynamics Approach to Metaphor and Metaphor-Led Discourse Analysis. Metaphor and Symbol 24(2), 63-89.

Castillo, I. (2019). Metáfora sistemática para pensar y escribir la educación chilena en columnas de opinión de cibermedios. Concepción, Chile: Universidad de Concepción.

Chilton, P. \& Ilyin, M. (1993). Metaphor in political discourse: the case of the 'common European house'. Discourse \& Society 4(1): 7-31. 
Deignan, A. (2005). Metaphor and Corpus Linguistics. Philadelphia, Estados Unidos: John Benjamins Publishing Company.

Digonnet, R. (2014). Power and Metaphor. Towards more Executive Power in American Presidents' Inaugural Addresses? Lexis 8: 1-22.

Ekaterina, P. (2016). Metaphor in political speeches of American and Russian presidents. Baltic Humanitarian Journal 5(4, N017): 108-110.

Escandell, M. V. (2007). Apuntes de Semántica Léxica. Madrid, España: Universidad Nacional de Educación a Distancia.

Fauconnier, G. \& Turner, M. (2008). "Rethinking metaphor". En Gibbs, R. (Ed.), The Cambridge Handbook of Metaphor and Thought (pp. 53-66). Cambridge, Inglaterra: Cambridge University Test.

Fuentes, C. (2020). Chile, cambio constitucional, crisis social y coronavirus. Agenda Pública, El país [en línea]. Disponible en: https://bit.ly/2CW5h9s. [Consulta 23/08/2020]

Gibbs, R. (2008). The Cambridge Handbook of Metaphor and Thought. Cambridge, Inglaterra: Cambridge University Press.

Gobierno de Chile. (2019]. Prensa Presidencia [en línea]. Disponible en: https://bit. ly/2DIM7q6. [Consulta 25/11/2019].

Gobierno de Chile. (2010). Biografía Presidente de la República - Sebastián Piñera Echenique [en línea]. Disponible en 2010-2014.gob.cl/presidente/. [Consulta 28/09/2020]

Güell, P. (2019). El estallido social de Chile: piezas para un rompecabezas. Mensaje 68(685), 8-14.

Lakoff, G. \& Johnson, M. (1980). Metaphors we live by. Chicago: The University of Chicago Press.

Landau, M., Robinson, M. \& Meier, B. (2014). "Introduction". En Landau, M., Robinson, M. \& Meier, B. (Eds.), The Power of Metaphor: Examining its influence on social life, pp. 3-16. Washington, DC.: American Psychological Association.

Leiva, B. (2020). Estallido social en Chile: la persistencia de la Constitución neoliberal como problema. DPCE Online 42(1).

Lesz, B. (2011). To shape the world for the better: an analysis of metaphors in the speeches of Barack Obama. Tromsø, Noruega: Universidad de Troms $\emptyset$.

Márquez, F., Pérez, M. \& Rodríguez, P. (2020). Culturas urbanas en ciudades latinoamericanas. Nuevas y antiguas miradas. Ensayos. Persona y Sociedad 34(1): 1-12.

Mejía, J. (2000). El muestreo en investigación cualitativa. Investigaciones sociales 4(5): $165-180$.

Navarro, F. \& Tromben, C. (2019)."Estamos en guerra contra un enemigo poderoso, implacable": los discursos de Sebastián Piñera y la revuelta popular en Chile. Literatura y lingüística (40), 295-324.

Paúl, F. (2019). Protestas en Chile: 4 claves para entender la furia y el estallido social en el país sudamericano. BBC News [en línea]. Disponible en: https://bbc.in/34tkFmh [Consulta 25/11/2019]. 
Penninck, H. (2014). An analysis of metaphor used in political speeches responding to the financial crises of 1929 and 2008. Gante, Bélgica: Universiteit Gent.

Pragglejaz Group. (2007). MIP: A method for identifying metaphorically used words in discourse. Metaphor and Symbol 22(1): 1-39.

Rajevic, M. (2020). Memorias urbanas en la periferia de Santiago. Develando violencias y resistencias en la ciudad. Persona y Sociedad 34(1): 137-157.

Real Academia Española (RAE). (2018). Diccionario de la Lengua Española. Madrid, España: RAE.

Reyes, C. (2019). Presidenta UDI: "Queremos decirle a Chile y a nuestro gobierno, no estamos disponibles para negociar mientras no cese la violencia". La Tercera [en línea]. Disponible en: https://bit.ly/37EaZqS [Consulta 25/11/2019].

Sepúlveda, P. (2019). ¿Qué tan desigual es Chile? Qué Pasa [en línea]. Disponible en: https:// bit.ly/37MKsYs [Consulta 25/11/2019].

Seung, E., Park, S. \& Jung, J. (2015). "Methodological approaches and strategies for elicited metaphor-based research; a critical review". En Wan, W. \& Low, G. (Eds.), Elicited metaphor analysis in educational discourse, pp. 39-64. Amsterdam, Holanda: John Benjamins Publishing Company.

Ungerer, F. \& Schmid, H. (2006). An introduction to cognitive linguistics. Harlow: Pearson Longman

Valida, K. (2015). Metaphor in Political Discourse. Baku, Azerbaiyán: Khazar University.

Xu, Z. \& Sharifian. F. (2017). Unpacking cultural conceptualizations in Chinese English. Journal of Asian Pacific Communication 27(1), 65-84.

\section{- Sobre los autores:}

Amanda Valenzuela-Valenzuela es Antropóloga Sociocultural y Magíster en Lingüística Aplicada. Se desempeña como Investigadora en Fundación Kimntrum. Sus principales áreas de investigación son estudios de género, temáticas LGBT+ y metáfora conceptual.

Ricardo Cartes-Velásquez es Médico, Psicólogo, Dentista, Magíster en Salud Pública, Magíster en Filosofía y Doctor en Ciencias Médicas. Se desempeña como Investigador Senior en Fundación Kimntrum trabajando en proyectos de investigación, desarrollo e innovación vinculadas a equidad y bienestar social.

- ¿Cómo citar?

Valenzuela-Valenzuela, A. \& Cartes-Velásquez, R. (2020). Metáforas presidenciales durante el estallido social chileno de 2019. Comunicación y Medios, (42), 44-55. https://doi.org/10.5354/0719-1529.2020.57685 